\title{
Programa de Trabalho do Setor de Administração Pública das Nações Unidas
}

\author{
Trad. Maria de Lourdes Modiano \\ Public Administration Newsletter $\left({ }^{\star}\right)$
}

PROGRAMa de trabalho do Setor de Administração Pública do Departamento de Assuntos Econômicos e Sociais das Nações Unidas baseia-se, nos têrmos de referência do Setor, nas resoluções da Assembléia Geral, especialmente nas de números 723 (VIII), 1024 (XI), 1256 (XIII) e 1530 (XV), bem como em resoluções do Conselho Econômico e Social (ECOSOC).

São as seguintes as funções do Setor de Administração Pú-
blica: (1)

a) promover a boa administração pública no tocante a desenvolvimento social e serviços governamentais;

b) organizar e realizar pesquisas especificas sôbre problemas e práticas administrativas com relação a estruturas governamentais, métodos administrativos, politicas e práticas de pessoal e, bem assim, divulgar os resultados dessas pesquisas entre os governos, através de seminários e outros certames internacionais, bem como através da publicação de manuais, guias, etc.

c) proporcionar apoio concreto a atividades de cooperação técnica no campo da administração pública.

O programa de trabalho, tal como adiante descrito, reflete apenas os requisitos minimos constantes das resoluções acima referidas. Demais, tendo em vista os limitados recursos, para 1966 e 1967 sòmente foi possível incluir um ou dois itens de cada uma das seções.

Conforme afirmou a resolução ECOSOC (*) n. ${ }^{*} 907$ (XXXIV), «sólidas estruturas e boa administração pública são requisitos essenciais para o progresso dos países em desenvolvi-

(*) Número 1 - Fevereiro/66.

(1) ST/SGB/128/Emenda 3 (23-6-1965).

(*) Conselho Econômico e Social (N.T.) 
mento». Nesse sentido, o critério aplicado na escolha de projetos foi sua possivel contribuição para os esforços dos governos no sentido de melhorar a administração para o desenvolvimento.

Em 1966 e 1967, dar-se-á maior ênfase aos seguintes pontos: (a) reforma administrativa, (b) treinamento no serviço público, (c) administração de desenvolvimento, e (d) certos aspectos de govêrno e administração locais, tais como aspectos administrativos da urbanização e aspectos administrativos da reforma agrária.

Outros órgãos de linha do Departamento de Assuntos Econômicos e Sociais das Nações Unidas foram consultados para a formulação dos projetos que lhes dizem respeito. Contudo, o programa de trabalho não inclui os aspectos administrativos de muitas atividades de desenvolvimento econômico e social, partindo do principio que êsses serão incluídos nos programas de trabalho de outros órgãos de linha e agências especializadas interessadas nos mesmos. O Setor de Administração Pública cooperará com outros órgãos e agências nesses projetos (2), especialmente na esfera do desenvolvimento regional, desenvolvimento de comunidade, habitação, serviços sociais, planejamento social administração sanitária, transportes. bem como em problemas financeiros. (3)

O Setor de Administração Pública também cooperará com instituições internacionais e nacionais no campo da administração pública, para a implementação de inúmeros projetos.

\section{A. GERAL}

A.1 - Desenvolvimento de programas de cooperação técnica em administração pública e apoio concreto aos mesmos.

- Isso inclui assistência no recrutamento de técnicos, apoio especifico aos técnicos, supervisão específica de programas de bôlsas e aspectos concretos da administração dos projetos do Fundo Especial em administração pública. Inclui, também, seleção e desenvolvimento de métodos eficientes de cooperação técnica em administração pública, bem como avaliação de resultados da cooperação técnica nesse setor.

- Autorização: Resoluções da Assembléia Geral Nos 723 (VIII) e 1024 (XI) .

(2) Veja-se projeto A. 3, adiante.

(3) O Setor Fiscal e Financeiro é responsável pelo trabalho sôbre administração do impôsto de renda e outros, com exceção da administração aduaneira. A incumbência do Setor de Administração Pública quanto ao trabalho de administração aduaneira não está relacionada como projeto separado, mas será levada a efeito como parte dos projetos A. 1, D. 1 e D. 2 . 
A.1.1 - Cessão de pessoal executivo e administrativo
(OPEX) $\left(^{*}\right)$

- Inclusive consultas sôbre aspectos de politicas e cessão de pessoal OPEX (tanto nos programas regulares como nos expandidos), pareceres sôbre requisições de assistência OPEX e respectiva implementação (juntamente com outras repartiçôes de linha do Departamento, segundo o caso), pareceres sôbre aspectos de politicas de designações individuais e responsabilidade especifica sôbre os relatórios de andamento e avaliação, quando necessário, da forma de assistência da OPEX em conjunto. Esse projeto será levado a efeito em cooperação com as Seções-área do BTAO (responsável pelos aspectos operacionais do programa OPEX), com outros órgãos de linha e com as agências especializadas interessadas.

- Autorização: Resoluções da Assembléia Geral, N ${ }^{\text {is }}$ 1256 (XIII), 1930 (XV) e 1946 (XVIII).

A.2 - Estudos e análises de problemas de administração pública, com particular referência ao desenvolvimento econômico e social, visando a prestar assistência aos governos, na implantação de uma boa administração pública (4)

- Inclusive elaboração e publicação de manuais, guias e monografias baseados em estudos comparativos de técnicas e sistemas de administração em várias regiões do mundo. Os projetos concretos serão relacionados neste item do programa. Trabalhos completos já concluídos incluem «Standards and Technique of Public Administration» (Publicação das Nações Unidas, 1951. II. B. 7) e «A Handbook of Public Administration» (Publicação das Nações Unidas 61. II. H. 2).

(*) Programa das Nações Unidas para a cessão de pessoal executivo e administrativo (N.T.)

(4) Esses estudos e análises ajudam, de um lado, a estabelecerem-se padrões que poderão ser utilizados no trabalho de desenvolvimento dos programas de cooperação técnica e de apoio aos mesmos. Por outro lado, êsșes estudos nos problemas amente a experiência dos técnicos das Nações Unidas, inclusive assim ligado ao Projeto 
- O trabalho planejado neste projeto inclui um estudo comparativo de programas importantes de reforma administrativa, com especial referência a fatôres de êx to dos esforços de reforma. Perspectivas de estudos a serem realizados em 1966, estudos de casos e análises para 1966 e 1967. Seguir-se-á uma reunião internacional de peritos para revisão do estudo. Documento a ser fornecido à ECAFE para uso em seu Seminário de Reforma Administrativa, em 1968.

- O trabalho que pode ser levado a efeito inclui um estudo sôbre o papel e o impacto das funções gerenciais nos governos modernos; como operam seus ocupantes e como pode ser aperfeiçoada sua capacidade de desempenhar a função; programas, igualmente, para desenvolvimento da capacidade administrativa, destinados a altos funcionários públicos.

- Autorização: Resoluções Nos. 723 (VIII) e 1.024 (XI), da Assembléia Geral.

- Prosseguimento do trabalho.

A.3 - Ação articulada com agências especializadas e outros órgãos especificos de funções de grande desenvolvimento e matérias correlatas.

- O trabalho envolve a colaboração de outros escritórios e agências, tais como FAO, ILO, OMS e UNESCO, bem como outras áreas específicas. O trabalho já realizado inclui vários projetos de cooperação com o Bureau de Assuntos Sociais e outras repartições especificas; colaboração com a Organização Pan-Americana da Saúde (O.M.S.), em estudos e seminários sôbre Organização e Administração de Serviços de Saúde Pública no Caribe e na América Latina; e o Seminário ONU/FAO no Cairo em 1964, sôbre Organização e Administração de Serviços Agrícolas nos Estados Árabes (ST/ $\mathrm{TAO} / \mathrm{M} / 24)$. Está prevista a continuidade da colaboração com essas e outras agências, na organização de seminários para altos funcionários de países em desenvolvimento, responsáveis pela administração das respectivas funções (veja-se Projeto D. 1, adiante).

- Inclusive um estudo para identificar elementos comuns em metodologia e conteúdo para serem usados como guias para a execução dos projetos inter-regio- 
nais sôbre administração e organização de funções superiores de desenvolvimento (tais como agricultura, educação, saúde, habitação, trabalhos, serviço social e transportes), a serem levados avante em colaboração com as agências especializadas e escritórios específicos interessados.

- Autorização: Resoluções Nọs 1024 (XI), e A/C, 2/ 189, da Assembléia Geral e A/C. 2/189, anexo, item 12.

A.4-Coleta, análise e intercâmbio de informações técnicas sôbre ADMINISTRAÇÃ, EM COLABORAÇÃO, QUANDO INDICADO, COM o Instituto Internacional de Ciências Administrativas (IIAS( e outras instituições apropriadas.

- Entre 1951 e 1954, o IIAS publicou vinte e quatro estudos com o apoio das Nações Unidas. Desde então as Nações Unidas passaram a dar uma modesta contribuição financeira à Revista do IIAS, hoje "International Review of Administrative Sciences», usando-a como veiculo de divulgação de informação.

- Cooperação também com a Associação Internacional

- de Ciência Política, União Internacional de Autoridades Locais, Organização Oriental Regional para Administração Pública e Centro Internacional de Informação para Crédito Local.

- Elaboração e revisão periódica de um catálogo de agências e instituições nacionais para o progresso da Administração Pública.

- Autorização: Resolução N` 723 (VIII), da Assembléia Geral.

- Prosseguimento dos trabalhos.

A. 5 - Convocação pelo Secretário-Geral de um grupo de peritos a intervalos regulares de alguns anos, para o exame e avaliação do programa de Administração Pública.

- A ser realizada na sede em 1967. O trabalho preparatório começará em 1966, com a consulta das agên cias especializadas e outros escritórios específicos.

- Autorização: ECOSOC, em sua Resolução N* 907 (XXXIV), tomou conhecimento do relatório E/3630 do Secretário-Geral, do qual constava fortc recomendação para a convocação dessas reuniões.

- Prosseguimento do trabalho. 
B. SERVIÇO CIVIL E ADMINISTRAÇÃO DE PESSOAL

B.1 - Assistência na adaptação dos sistemas nacionais de serviço civil e assistência no aperfeiçoamento da administração de pessoal.

- Inclusive estudos comparativos de estrutura, legislação, recrutamento, têrmos e condições de serviço e vulto do serviço civil.

- Manual de Leis e Praxes do Serviço Civil (Handbook of Civil Service Laws and Practices) está sendo terminado e sua publicação programada para 1966.

- Elaboração de um manual sôbre métodos de seleção e promoção no serviço público, inclusive concursos, entrevistas, apuração do merecimento, etc., baseado num estudo comparativo. O Projeto será iniciado em 1966 ou 1967.

- Estudo comparativo a ser iniciado sôbre o problema da adaptação dos sistemas de serviço civil nos países em desenvolvimento para ajustá-lo aos recursos e necessidades dos programas de desenvolvimento nacional.

- Estudo comparativo de órgãos centrais de pessoal (nacionais) dos países em desenvolvimento: suas funções, localização, estrutura e pessoal; suas relações com os legislativos, chefes de Estado e chefes de ministérios e emprêsas públicas; seus serviços às operações diárias de pessoal no govêrno.

- Autorização: Resoluções Nos 723 (VIII) e 1024 (XI), da Assembléia Geral; Resoluções Nos 907 (VIII) e 1024 (XI), da ECOSOC.

- Prosseguimento do trabalho. 